\title{
O SUJEITO QUE CUIDA DO OUTRO: SEUS DISCURSOS E PRÁTICAS EM SAÚDE
}

\author{
THE SUBJECT THAT TAKES CARES OF THE OTHERS: ITS SPEECHES AND PRACTICES IN HEALTH
}

\author{
Maria Angélica Gazzana de Lucena* \\ Jayme Paviani*
}

\section{RESUMO:}

A leitura que se pretende aqui realizar é sobre aquele sujeito que cuida do outro, no campo da saúde, tornada campo de problematização, em diálogo com Foucault. Guardado o aspecto de como cada profissional se movimenta nesse campo, se usa ao profissional Enfermeiro o que cuida do outro. Nesse propósito, e para também compreender os seus modos de ser, viver e trabalhar se faz uma aproximação às contribuições de Foucault no que se refere às noções de sujeito, poder, discurso e que se entende podem contribuir para elucidar outros aspectos, no que tange às condições sociais dos espaços em que se encontra o sujeito que cuida do outro. Nesse modo de relatar e abordar esse sujeito que cuida do outro, se remete a referenciais que envolvem a construção discursiva de seu "saber-fazer cuidado" em saúde, ainda que em linhas gerais. $\mathrm{O}$ argumento de fundo é o de que esse sujeito que cuida do outro se encontra inserido, histórica e socialmente, na trama complexa das relações e mantido por uma rede de poderes que se observa na atualidade.

PALAVRAS-CHAVE: Sujeito. Práticas em saúde. Poder. Discursos. Foucault.

ABSTRACT: The reading that is intended here is that subject that takes care of the other, in the health field, made problematization field, in dialogue with Foucault. Saved the aspect of how each professional is moving in that field, it is used to the professional Nurse who takes care of the other. In this purpose, and also for their modes of being, living and working towards an approximation to Foucault's contributions in terms of the subject notions, power, speech and can be understood as contributing to elucidate other aspects in reference to social conditions of space where is the subject that takes care of the other. In this way of reporting and approaching this subject that takes care of the other, send a referential that involves a discursive construction of its "knowing - to do care" in health, although in general lines. The underlying argument is that the subject that cares for the other is inserted, historically and socially, in the complex plot of relationships and maintained by a network of powers that is observed today.

KEYWORDS: Subject. Practices in health. Power. Speeches. Foucault.

\footnotetext{
* Mestra em Filosofia (UCS). Bacharel em Enfermagem, com Pós-Graduação em Educação na Saúde pelo Instituto Sírio Libanês de Ensino e Pesquisa (SP) e pela Escola de Saúde Pública Sérgio Arouca (FIOCRUZ RJ). E-mail: angelica.gazzana@gmail.com.

Doutor em Linguística e Letras, com estudos de Pós-Doutorado em Padova - Itália. Licenciado em Filosofia, Ciências Jurídicas e Sociais. Doutor Adjunto da Universidade de Caxias do Sul (UCS). E-mail: jayme.paviani@ucs.com.
} 


\section{INTRODUÇÃO}

Discussões sobre o conceito de sujeito permanecem presentes no pensamento ocidental moderno e contemporâneo. Em uma "varredura" do significado desse conceito, encontram-se diversos sentidos, do gramatical ao metafísico. Respeitadas suas concepções, no sentido geral do termo, encontra-se em Abbagnano que o sujeito é "aquilo de que se fala ou a que se atribuem qualidades ou determinações ou a que são inerentes qualidades ou determinações; ou o eu, o espírito ou a consciência, como princípio determinante do mundo do conhecimento ou da ação, ou ao menos como capacidade de iniciativa em tal mundo" (ABBAGNANO, 2007, p. 929).

$\mathrm{Na}$ intenção de pensar sobre o sujeito na condição daquele que cuida do outro, tendo como foco as relações entre filosofia e saúde, buscamos a concepção de sujeito trazida por Foucault, para, então, nos aproximarmos daquele sujeito cuidador. Sem pretender minimizar a importância dos aspectos outros que envolvem a questão do sujeito em Foucault, como, por exemplo, as que se relacionam à constituição do sujeito por si mesmo no que tange à sexualidade, no uso de seus prazeres, ou "do como" se dá a constituição do sujeito ou, ainda, do problema do transcendental, fazemos uma aproximação ao tema da constituição do sujeito por si mesmo trazida por Foucault e que se alcança na discussão aqui proposta.

No pondo em que a questão se volta ao pensamento teórico e prático do profissional Enfermeiro, enquanto sujeito que cuida do outro, no campo da saúde e seus modos de "fazer cuidado", inserem-se alguns apontamentos, certos deslocamentos, acontecimentos, recortes de uma trajetória conceitual que acompanharam os discursos em seus diferentes contextos históricos e que marcaram a construção de um saber-fazer - cuidado inerente à profissão de Enfermagem, na compreensão "de como as enfermeiras se transformaram naquilo que são"

\section{Do sujeito em Foucault}

[...] atrás das coisas há "algo inteiramente diferente": não seu segredo essencial e sem data, mas o segredo [de] que elas são sem essência, ou que sua essência foi construída peça por peça a partir de figuras que lhe eram estranhas. (FOUCAULT, 1999, p. 18).

\footnotetext{
${ }^{1}$ Expressão tirada de Kruse (2003, p. 49).
} 
Acerca da concepção de sujeito trazida por Foucault, inicialmente se apresenta que Foucault foi contrário à ideia de se fazer previamente uma teoria do sujeito, uma teoria $a$ priori do sujeito, o sujeito enquanto dado universal e a-histórico. Foucault nos fala de um sujeito pensado em função da singularidade histórica e cultural do seu tempo. O sujeito não é uma invariante, uma essência fixa, acabada e idêntica a si mesma, mas uma forma constituída com e pelas experiências históricas. Nesse entendimento, e no que diz respeito ao sujeito de conhecimento, em oposição à ideia cartesiana daquele sujeito dado, de um sujeito puro $e a$ priori de conhecimento, Foucault sugere um sujeito que é constituído de diversas formas, em diferentes momentos históricos.

$\mathrm{Na}$ esteira de Nietzsche e sua genealogia, Foucault estuda a história das instituições disciplinares (o hospital, a prisão, a fábrica, a escola) que surgiram na modernidade e pensa a constituição do sujeito a partir de formas de discursos e de relações de poder. A problemática do sujeito, em Foucault, nas palavras de Castro (2009, p. 407-408): "Seja quando se trate da experiência da loucura, do nascimento da clínica, da arqueologia das ciências humanas, da história do castigo, das disciplinas ou da sexualidade", é uma "história do sujeito" ou, antes, do que ele denomina modos de subjetivação, que mudou de estilo, de objetos e de metodologia, em que "os modos de subjetivação são, precisamente, as práticas de constituição do sujeito". Essas práticas referem-se às formas pelas quais o sujeito se constitui.

Assunto presente ainda em seu texto, O sujeito e o poder (1995, p. 231-249), em que afirma que o sujeito constitui o tema geral de suas pesquisas, Foucault postula que o sujeito é histórico, mas produzido na sua própria história e pela história que o permeia através do que denominou de uma "história da verdade". Conforme situada por Castro (2009, p. 203-204), a relação entre sujeito e história aparece desde a primeira obra de Foucault, Maladie mentale et personnalité (1954), " "quando trata da origem da doença mental a partir das contradições da história concreta do indivíduo"; e "falar de história, em Foucault, é falar do sujeito e, vice-versa, falar do sujeito é falar da história”. Dois aspectos (objeto de descrição e questão metodológica), portanto, que se encontram entrelaçados.

De suas entrevistas, retira-se A ética do cuidado de si como prática da liberdade, na qual Foucault (2004, p. 268) afirma que o sujeito “é uma forma, e esta forma não é, sobretudo, sempre idêntica a ela mesma". E enquanto modos ou formas, estas se modificam num momento e noutro. Assim, a forma do sujeito na Antiguidade é diferente da forma do

\footnotetext{
${ }^{2}$ Nessa obra, encontramos essa problemática; o capítulo III intitula-se "A enfermidade e a história individual (CASTRO, 2009, p. 203).
} 
sujeito na Modernidade. Mas, diz Foucault: "as formas pelas quais os sujeitos se constituem não são alguma coisa que o indivíduo "invente", mas [...] esquemas que ele encontra em sua cultura e que lhe são propostos" (CASTRO 2009, p. 276).

Nesse sentido, Foucault propõe um sujeito que é constituído de diferentes formas, nos diversos momentos históricos, sem identidade fixa, em um processo permanente, uma forma nunca idêntica a si mesma, que não deixa de "se deslocar" e de se transformar. Disso é possível inferir que o sujeito não é uma invariante, uma essência fixa, acabada e idêntica a si mesma, mas uma forma constituída com e pelas experiências históricas.

Retomando as palavras de Gros (2008), encontram-se três caminhos possíveis para se abordar a questão do sujeito enquanto sujeito constituído historicamente, como propõe Foucault e não como sujeito constituído, quais sejam: o sujeito que é constituído teoricamente por uma série de saberes - científicos ou não - como objeto a ser conhecido; o sujeito constituído - jurídica ou positivamente - por meio de certas práticas institucionais de poder, como objeto a ser dominado; e o sujeito constituído pelo próprio indivíduo, por meio das práticas de si, isto é, o sujeito no âmbito de sua autoconstituição, ou, como dito por Gros (2008, p.128): a "história do olhar a partir do qual eu me constituo para mim mesmo como sujeito".

Assim pontuado, a questão do sujeito pode ser tratada a partir dos discursos científicos que se desenvolvem sobre ele. Tal é a temática de As palavras e as coisas que procura investigar de que modo o sujeito vai se definir como indivíduo falante, vivo, trabalhador. E "uma vez que ele fala, trabalha e vive, acha-se, no seu próprio ser, inteiramente misturadas a histórias que não lhe são nem subordinadas nem homogêneas" (FOUCAULT, 1999, p. 478-479). Mas os discursos não se limitam às palavras, ou às coisas. Para além da designação dos signos, o discurso é também a formação e a disposição desses signos com relações de poder, hierarquias, procedimentos de exclusão, de controles internos ao discurso. É uma prática, que constrói seu sentido nas relações e nos enunciados. Não é, portanto, uma unidade monolítica.

E o que, então, Foucault entende por discurso? Conforme se encontra em Arqueologia do Saber, o discurso é assim definido por ele:

Um conjunto de enunciados, na medida em que se apoiem na mesma formação discursiva [...] Além de ser histórico fragmento de história, unidade e descontinuidade na própria história, que coloca problemas de seus limites, de seus cortes, de suas transformações, dos modos específicos de sua temporalidade, e não 
de seu surgimento abrupto em meio às cumplicidades do tempo. (FOUCAULT, 2007, p. 132-133).

Desse modo, se pode falar de discurso clínico, discurso econômico, discurso da história natural, discurso psiquiátrico. Por fim, Veyne (2011, p. 16-17) nos diz: "O discurso para Foucault é "algo muito simples: é a descrição mais precisa, mais concisa de uma formação histórica em sua nudez, é a atualização de sua última diferença individual”.

Outro caminho possível para se compreender a questão da constituição do sujeito moderno em Foucault, como apontado, se dá a partir do estudo das instituições e os princípios sociais, dos asilos, das prisões, dos dispositivos de controle, das relações entre saber e poder. A partir de práticas de poder, tal como tratada na História da loucura, Vigiar e punir, A vontade de saber, e de onde se tem um sujeito enquanto objeto de saber e de dominação, enquanto doente, louco, delinquente, homossexual. E por práticas, em resumo, Foucault entende: a "racionalidade ou a regularidade que organiza o que os homens fazem como sistemas de ação na medida em que estão habitados pelo pensamento" (DE4, 580), que tem um caráter sistemático (saber, poder, ética) e geral (recorrente) e, por isso, constituem uma “experiência" ou um "pensamento" (CASTRO, 2009, p. 338).

Onde a questão se volta ao tema do poder, é necessário dizer que Foucault não o apresenta como uma teoria do poder, mas como uma "analítica do poder". Se antes de Foucault o poder esteve associado, mais comumente, à figura da Igreja ou do Estado e as discussões se davam em como legitimar o poder de uns (poucos) sobre outros (muitos) e, assim, manter a ordem social, Foucault pergunta não o que é o poder, mas como ele funciona. Ele entende o poder não como um objeto natural, mas uma prática social, expressa por um conjunto de relações e diz:

\footnotetext{
As relações de poder enraízam-se no conjunto da rede social. Isto não significa, contudo, que haja um princípio de poder, primeiro e fundamental que domina até o menor elemento da sociedade [...] Mas, antes, porque se produziu uma estatização contínua das relações de poder. (FOUCAULT, 1995, p. 247).
}

Nessas condições, o poder passa a ser tratado a partir das relações que ele engendra e impulsiona no cotidiano, no âmbito das práticas humanas. Dessa maneira, em uma visão de conjunto, o tema "poder" faz referência a outros conceitos, como o de poder pastoral, biopoder, biopolítica, disciplina, governo, liberalismo, medicalização, polícia e razão de Estado, panóptico, luta. Como se encontra em Castro: "Para Foucault, o poder não é uma 
substancia ou uma qualidade, algo que se possui ou se tem; é, antes, uma forma de relação" (CASTRO, 2009, p. 326).

A partir disso, não se pode falar em "um poder", mas, antes, descrever as relações de poder. E essas relações são sutis, múltiplas, que se dão em diversos níveis. Há relações de poder em todas as relações entre os sujeitos, entendidas como "um conjunto de ações que tem por objeto outras ações possíveis, operam sobre um campo de possibilidades: induzem, separam, facilitam, dificultam, estendem, limitam, impedem (CASTRO, 2009, p. 327)". O tema do poder, conforme sugere Castro, é para Foucault: "um modo de enfrentar o tema do sujeito" em que o termo sujeito pode ser compreendido como o "sujeito submetido, pelo controle e dependência de outro"; e "o sujeito ligado à própria identidade pelas práticas e pelo conhecimento de si” (CASTRO, 2009, p. 324-326).

Nesse momento, a partir da imersão do filósofo em textos da Antiguidade Clássica, o problema que se coloca Foucault, segundo Frédéric Gros (2004, p. 618) é o da possibilidade de pensar práticas de si e também práticas da verdade, em que estaria em jogo uma espécie de liberação do sujeito, muito mais do que seu aprisionamento: trata-se, em suma, da pergunta sobre a possibilidade de um sujeito pensado não apenas no sentido de uma sujeição, mas de uma subjetivação ou, antes, do que Foucault denomina modos de subjetivação, ou "formas de atividade sobre si mesmo", e que se referem, de forma geral, às relações que são definidas de si para consigo. E os modos de subjetivação são, precisamente, as práticas de constituição do sujeito, conforme nos coloca Castro (2009, p. 407-408).

A objetivação e a subjetivação são, portanto, processos que se complementam e que se relacionam por meio do que Foucault denominou de "jogos de verdade" - presente na introdução de História da sexualidade: o uso dos prazeres (1984) - que são os modos pelos quais os discursos podem ou não se tornar verdadeiros de acordo com as circunstancias em que são ditos ou a maneira pela qual um tipo de objeto se relaciona com o sujeito. Ao perceber a relação entre saber e poder, Foucault nos fala de como os saberes se tornam dispositivos políticos que auxiliam os mecanismos de poder, e de onde a ideia de sujeito é o sujeito dos mecanismos de poder, na medida em que ele é constituído pelas técnicas de sujeição, um sujeito-sujeitado, aquele constituído enquanto objeto de saber e objeto de dominação. 


\section{A construção discursiva de um saber-fazer-cuidado}

No campo da saúde circulam diferentes saberes e práticas, o que leva a diferentes modos de "fazer cuidado" e modos de ser profissional. Esses saberes, que compõem um conjunto de conhecimentos, se concretizam nesse "fazer cuidado" e se traduzem no cuidado com o outro. Mas, e o que é esse "fazer cuidado"? Pode-se designá-lo da seguinte maneira: o "fazer cuidado", quando associado ao tema da saúde, se caracteriza por uma atitude e ações que envolvem a apropriação das tecnologias do cuidado, enquanto recursos, procedimentos, técnicas que têm como objetivo final uma terapêutica exitosa. Importante destacar que remete a um determinado momento histórico - social, cultural, político e tecnológico no campo da saúde (SANTOS; WESTPHAL, 1999).

Além disso, há que se considerar que os múltiplos saberes se movimentam nas relações de poder entre os diferentes profissionais. E o modo como essas relações de saberpoder se dão entre eles, por sua vez, contribui para as concepções que se tem sobre essa ação, essa prática, esse fazer. Concepções essas que se entrelaçam nas tramas sociais históricas, como assinalado por Foucault, e que orientam um modo de ser e viver, pois permeadas de discursos que transpassam na subjetividade dos sujeitos. Podem-se incluir aqui os discursos sobre o profissional Enfermeiro e suas práticas de cuidado, entendendo-se que os discursos possuem um suporte histórico e institucional, que permite ou não sua realização.

Ao examinar tal temática, primeiramente se aceita que a Enfermagem, enquanto campo de estudos, e uma prática social, é uma prática historicamente estruturada, constituída por diferentes maneiras de cuidar, sendo que esse "cuidado" encontra-se diretamente relacionado com os discursos de cada momento histórico. Nasce no século XIX, tendo como autora a enfermeira Florence Nightingale, na Inglaterra e apresenta também grandes diversidades na forma como se organiza, procurando construir para si instrumentais teóricos e técnicos, como nos expõem Ramos (2007, p. 37-41):

\footnotetext{
A consolidação da profissão no cenário internacional é modificada por inúmeras condições, entre as quais a possibilidade de sustentar-se no meio acadêmicocientífico como capaz de emitir discursos coerentes sobre si, sobre sua posição na sociedade e no empreendimento coletivo da ciência.
}

Assim, em "seus primórdios", expressão essa bem conhecida no meio acadêmico e fora dela, a Enfermagem foi marcadamente influenciada pela escola anglo americana e atrelada à figura de Florence Nightingale. Em seu surgimento, conforme nos conta Silva 
(1989), a Enfermagem vincula-se às atividades domésticas realizadas pelas mulheres da família, por monjas e ou escravas, por serem já as responsáveis pelo cuidado das crianças e dos idosos. Identifica-se que em um tempo cronológico do Brasil Colonial e Imperial predominava o discurso religioso e o cuidado, portanto esteve relacionado à caridade e ficava a cargo de entidades filantrópicas e beneficentes ligadas à Igreja Católica, como as Santas Casas de Misericórdia.

Já a conhecida Enfermagem moderna ou científica (início do século XX) nasce como uma prática coadjuvante da prática médica e, por isso, loco instituída ao redor de práticas institucionalizadas, marcadamente em contextos hospitalares. Sobre isso, ainda presente no pensamento de muitos estudantes de Enfermagem, quando do ingresso na Graduação, uma concepção de prática profissional "circunscrita" e situada basicamente nesse contexto de atuação, o hospitalar. Lembremos que, em sua história, o hospital, como local de reclusão e morte, era um local destinado aos pobres, que não tinham outro lugar para morrer, e seu principal objetivo era a assistência espiritual. A partir do século XX, com o avanço científico e tecnológico, tornou-se um local terapêutico e de produção de conhecimento. Foucault em Arqueologia do saber (2007), o define como uma das instituições de sequestro com a função, entre outras, do controle dos corpos.

Sabe-se que na época, início do século XX, o panorama sanitário em que se encontrava o Brasil e a América Latina com a ocorrência de doenças transmissíveis (como a lepra, a cólera, a tuberculose, a febre amarela, a peste bubônica, a varíola, a febre tifoide), e outros fatores como a industrialização e a urbanização das cidades levou o governo a preocupar-se com a elaboração de políticas de saúde de ordem sanitarista o que, por sua vez, exigiu implementação de modelos de atenção à saúde voltados às práticas sanitaristas. Concomitante a esses acontecimentos, deu-se a criação de um Serviço de Enfermeiras no Departamento Nacional de Saúde Pública (DNSP) e a criação de uma Escola de Enfermeiras junto ao mesmo, a Escola de Enfermagem Anna Nery (1923). ${ }^{3}$ O modelo adotado e transmitido no referido período era o anglo-americano.

Até a década de sessenta, as Escolas de Enfermagem funcionavam em regime de internatos, seguindo o modelo anglo americano e cumprindo, com isso, o seu papel disciplinador e regulador de condutas das enfermeiras, sendo esse aspecto assunto de vários estudos na área. Disso se tem a necessidade de uma ordem que se impunha para dentro do

\footnotetext{
${ }^{3}$ Em 1926 a escola passou a chamar-se Escola Anna Nery e posteriormente Escola de Enfermagem Anna Nery da atual Universidade Federal do Rio de Janeiro.
} 
hospital e que o pessoal de enfermagem fosse disciplinado, e sua prática profissional, do mesmo modo, organizada.

O modelo educacional exercido e conduzido (modelo anglo-americano) pelas enfermeiras americanas, consideradas pioneiras, caracterizado pelo estudo sistemático das doenças e pelo "cuidado ao doente", era o ideal transmitido de uma "boa enfermeira", modelo esse ainda reproduzido como um "ideal de comportamento", um perfil a ser seguido e aspirado por aqueles que pretendem a profissão de Enfermagem. Esse modelo, introduzido por Florence Nightingale, tinha por objetivo a implementação da técnica disciplinar, do disciplinamento dos trabalhadores (as enfermeiras) e de suas tarefas, sob direção médica.

Com respeito a esse modelo, Lunardi $(1997 ; 1999)$ ao estudar os saberes e as práticas morais da história da Enfermagem identifica a sua contribuição e alguns elementos que podem estar ainda presentes nas práticas atuais, mesmo que em diferentes formatos. Disso advêm as referências quanto aos quesitos honestidade, sobriedade, espírito de organização, religiosidade, devoção, fidelidade, elegância e delicadeza, habilidade para a observação minuciosa, como atributos de uma "enfermeira confiável".

Como participante de todo um processo social, a Enfermagem moderna brasileira teve importante papel relacionado ao conhecimento e organização interna de espaços, sobremaneira o do hospitalar, como mencionado. Na área da Enfermagem Psiquiátrica, por exemplo, que nasceu no hospício e como executora de uma ordem disciplinar médica, a necessidade de organização desse espaço determinou a criação da primeira escola de enfermagem ligada ao Hospital Nacional de Alienados, a Escola Profissional de Enfermeiros e Enfermeiras, criada através do Decreto n. 791 de 27/9/1890. Inspirada no modelo francês (que não seguia o modelo Nightingale), tinha, entre seus objetivos, a preparação de pessoal para o trabalho de cuidar dos alienados num espaço "medicamente" concebido.

Sobre essa particularidade que aqui se contextualiza para ilustrar a trajetória da enfermagem brasileira e de seus modos de saber-fazer-cuidado (e que se entende e se repete em alguma medida em outras áreas), em uma aproximação aos textos de Foucault que constam em Microfísica do poder (1999), ao responder sobre quem coordena a ação dos agentes da política do corpo, assim o autor expõe:

Tomemos o exemplo da filantropia no início do século XIX: pessoas que vêm se ocupar da vida dos outros, de sua saúde, da alimentação, da moradia. Mais tarde, desta função confusa saíram personagens, instituições, saberes [...] uma higiene pública, inspetores, assistentes sociais, psicólogos. E hoje assistimos a uma proliferação de categorias de trabalhadores sociais. (FOUCAULT, 1999, p. 151). 
Com a "nova onda americana", a partir da década de setenta, a Enfermagem brasileira assimilou as teorias de enfermagem, as quais representam um corpo de conhecimentos próprios, elevando a profissão a uma condição autônoma e, assim, ocupando certo status social. Na atualidade, o trabalho de enfermagem integra-se a um trabalho coletivo e a formação de Enfermagem, em nível de Graduação, vem sendo rediscutida em função das mudanças nas políticas de saúde e nos modelos assistenciais.

E assim se organizaram os saberes da profissão, saberes esses vinculados à prática médica e ao modelo biomédico, voltados ao "tratamento" e "cura" de uma parte do corpo de um indivíduo, este dependente e passivo, necessitado de cuidado e presente em discursos e práticas não tão distantes das atuais, reproduzidos por muitos profissionais no cotidiano de seus contextos de atuação. Enquanto profissional Enfermeiro se é herdeiro dessa concepção de "boas enfermeiras", de um modelo biomédico como paradigma de ensino e assistência e onde o tecnicismo se mostra como forma de organização de trabalho.

\section{A categoria cuidado e as práticas em saúde}

No âmbito profissional da saúde, a categoria "cuidado" encontra-se inserida no "saber - fazer" dos diferentes profissionais que a compõem, porém difere na sua forma de expressão e na multiplicidade de cenários, como lócus de ações de cuidado, embora atrelada a um bem valioso em si, a vida humana. Seu conceito é bastante abrangente e incorpora significados diversos, desde significados como desvelo, solicitude, diligência e atenção, zelo, e que se concretiza no contexto das relações sociais.

A palavra "cuidado" vem do latim, no sentido de cura - que expressa atitude de cuidado, desvelo, de preocupação e de inquietação pela pessoa amada ou por um objeto de estimação; e outra, derivada de cogitare-cogitatus que tem o mesmo significado de cogitar, pensar, colocar atenção, mostrar interesse, revelar atitude de desvelo e de preocupação. Também diferentes são as perspectivas que caracterizam as discussões sobre os sentidos do cuidar, como a filosófica, a técnica-instrumental, a política, a cultural, a ética. As características que cerceiam as práticas de saúde e estruturam a noção de cuidado intrínseca a elas transita por diferentes abordagens conceituais e metodológicas.

E pensar sobre o cuidado passa, sobremaneira, por uma reflexão filosófica, pois que fortifica os saberes que participam do corpus de conhecimento das disciplinas na área da saúde. Remete-se ao pensamento de Martin Heidegger (1889-1976) ao referir-se ao “dasein”, 
ao "ser-aî", aquele "ser lançado" no mundo, em uma dialética de presente, passado e futuro, numa construção sempre em curso e que tem como substrato a linguagem e, como "artesão", o "cuidado" (sorge). Nessa perspectiva, o "fazer cuidado", ou o ato de cuidar, diz respeito a uma atitude, a um modo de "ser-no-mundo", a "ser-com", a "ser-em-relação", adotado pelo ser humano em relação à sua ação e ao fenômeno da vida em sua totalidade.

Referindo-se ao cuidado em Enfermagem, no modelo introduzido por Florence Nightingale e que tinha por objetivo a implementação da técnica disciplinar, todo o "cuidado" voltava-se a um espaço geográfico, onde limpeza, boa ventilação, luz, calor colaboravam para a "cura do doente". Também sob a influência de Florence, conforme pesquisa de Almeida (1989, p. 40), conhecida, entre outras qualidades, por sua grande habilidade na resolução de problemas e pelos seus registros sistemáticos dos mesmos, quando seus métodos de trabalho chegam aos hospitais de Londres e Paris, ocorre o encontro entre "as práticas médica e de enfermagem no mesmo espaço geográfico - o do hospital, e no mesmo espaço social - o do doente". Como observou Foucault (1999), a Medicina urbana que se organizou no século XVIII não era propriamente uma medicina de corpos e organismos, mas das coisas como a água, o ar, as decomposições, os fermentos. E assim eram as práticas de Enfermagem.

De um salto, no transcorrer do século XX observou-se a diminuição das doenças transmissíveis e o aumento das doenças degenerativas, devido essencialmente às melhorias nas condições gerais de vida (DARDET apud SANTOS; WESTPHAL, 1999, p. 74). Isso provocou o deslocamento de uma ênfase curativa (paradigma do curativismo, defendido por Flexner, centrado na especialização) para um modelo de prevenção (paradigma da produção social da saúde) o que repercute também em um novo modelo de ensino e formação de profissionais de saúde. Na atualidade, os discursos que circulam na saúde é o da interdisciplinaridade, noção aqui trazida conforme a considerada por Paviani (2005, p. 20), a qual "pode ser praticada na atuação profissional, especialmente quando se requer a busca e a sistematização de conhecimentos provenientes de diversas áreas do conhecimento para resolver problemas reais".

Com efeito, a categoria cuidado também pode ser entendida como assistência, como "cuidado técnico" e, nesse modelo de assistência, de "fazer cuidado", a reorganização do processo de trabalho em Enfermagem, em novos moldes, passa pela integralidade de suas ações e inclui a abertura de espaços democráticos, que visam a ampliar escutas e trocas entre o que cuida e o ser do cuidado, o paciente. Nessa direção, diversos estudiosos do fazer em saúde definem o papel do profissional de saúde, na atualidade, como cuidador, o que implica 
a substituição do termo "tratar" pelo "cuidar", de onde "tratar" pressupõe um diagnóstico e “cuidar" tornaria possível uma visão ampliada do sujeito alvo dos cuidados (AYRES, 2001; MANDÚ, 2004).

Em tempos atuais e tendo como paradigma o modelo biopsicossocial, o cuidado em saúde envolve a contínua reconstrução de significados a respeito de si, do outro e do mundo, como também dos significados sobre saúde e doença, de um saber-fazer-cuidado, em um olhar que vá além da doença que o outro apresenta como observa Mandú (2004), considerando-se o conhecimento que possui sobre si mesmo, sobre o adoecer e a saúde, como focos essenciais na reconstrução conjunta de sentidos em direção a uma vida saudável nos seus diversos aspectos.

\section{Considerações finais}

A realidade que se apresenta e as profundas mudanças que vêm ocorrendo no domínio da saúde e no processo do cuidado, levam à necessidade de se ampliarem discussões que venham a compreender a dinâmica dos sujeitos envolvidos nesse processo, ou, dito de outra forma, daquele sujeito que cuida ao encontro de outro sujeito, o ser do cuidado, e entre esses e os diversos lócus das práticas em saúde, pois envolvem relações perpassadas por questões intrapsíquicas, psicossociais e institucionais. O "saber-fazer cuidado" no processo de trabalho, como um todo, abrange, além das relações interpessoais, a percepção de si e do meio, entre modos de vida pessoal e profissional, diferentes vivências e histórias de vida.

Aceitando que o papel da Filosofia também é o de refletir acerca das questões do já conhecido para compreender e redimensionar tais questões, a categoria cuidado e alguns dos seus significados foram trazidos, como um recurso analítico para se indagar sobre os modos de "fazer cuidado" daquele sujeito que cuida do outro, no campo da saúde, em seus diferentes momentos históricos. Modos esses inseridos em espaços tensos por estarem habitados por diferentes formações discursivas, pela verticalidade de poder e modelos hierarquizados de funções. Logo, espaços nos quais se encontram presentes tanto a subjetividade humana como os fatos objetivos. Importante também pontuar que as formas de subjetivação do sujeito encontram-se situados no campo do trabalho, este entendido não apenas como uma atividade, mas também como produtor de modos de ser, e que constitui um si, pelo qual o sujeito se reconhece. 
Assim posto, nos parece plausível se pensar sobre o sujeito que cuida do outro e suas práticas em saúde, tendo o cuidado intrínseco a elas, já que as práticas em saúde são, mesmo na atualidade, marcadas pela objetivação do outro, pela fragmentação do corpo humano e pela especialização dos saberes sobre ele, pelo distanciamento e não reconhecimento das singularidades e pela intermediação tecnológica das relações. Práticas em saúde que também se acredita significam legitimar a fragmentação do sujeito social contemporâneo.

Se a medicalização das sociedades implicou relações hierárquicas e disciplinadoras, acreditamos que o pensamento de Foucault nos ajuda na reflexão do que somos, sem com isso apresentar verdades absolutas daquilo que somos historicamente, mas sempre em movimento e problematização. Cabe perguntar o sentido que o cuidado adota nos seus diferentes contextos.

\section{REFERÊNCIAS}

ABBAGNANO, Nicola. Dicionário de filosofia. 5. ed. São Paulo: Martins Fontes, 2007.

ALMEIDA, Maria Cecilia Puntel de; ROCHA, Juan Stuardo Iazlle. O saber da enfermagem e sua dimensão prática. 2. ed. São Paulo: Cortez, 1989.

AYRES, José Ricardo de Carvalho Mesquita. Sujeito, intersubjetividade e práticas de saúde. Ciência \& Saúde Coletiva, v. 6, n. 1, p. 63-72, 2001.

CASTRO, Edgardo. Vocabulário de Foucault: um percurso pelos seus temas, conceitos e autores. Tradução de Ingrid M. Xavier. Belo Horizonte: Autêntica, 2009.

DREYFUS, Hubert; RABINOW, Paul. Michel Foucault: uma trajetória filosófica. Rio de Janeiro, Forense Universitária, 1995.

DREYFUS, Hubert. O sujeito e o poder. In: RABINOV, Paul; DREYFUS, Hubert. Michel Foucault: uma trajetória filosófica para além do estruturalismo e da hermenêutica. Rio de Janeiro: Forense Universitária, 1995. p. 231-249.

FOUCAULT, Michel. Vigiar e punir: nascimento da prisão. Tradução de Raquel Ramalhete. Petrópolis/RJ: Vozes. 1987.

FOUCAULT, Michel. História da sexualidade: o uso dos prazeres. Tradução de Maria Thereza da Costa Albuquerque. Rio de Janeiro: Graal, 1984. v. 2.

FOUCAULT, Michel. Microfísica do poder. 14 ed. Rio de Janeiro: Graal, 1999.

FOUCAULT, Michel. As palavras e as coisas: uma arqueologia das ciências humanas. Tradução de Salma Tannus Muchail. $8^{a}$ ed. São Paulo: Martins Fontes, 1999. (Coleção tópicos). 
FOUCAULT, Michel. A Arqueologia do saber. Rio de Janeiro: Forense, 2007.

FOUCAULT, Michel. A hermenêutica do sujeito. São Paulo: Martins Fontes, 2004.

GROS, Frédéric. O cuidado de si em Michel Foucault. In: RAGO, Margareth; VEIGA-NETO, Alfredo (Org.). Figuras de Foucault. Belo Horizonte: Autêntica 2008.

GROS, Frédéric. Situação do curso. In: FOUCAULT, Michel. A hermenêutica do sujeito. Tradução de Márcio Alves da Fonseca e Salma Tannus Muchail. São Paulo: Martins Fontes, 2004.

HEIDEGGER, Martin. A cura como ser da presença. In: HEIDEGGER, Martin. Ser e tempo. Petrópolis/RJ: Vozes, 1997. p. 243-300.

KRUSE, Maria Henriqueta Luce. Os poderes dos corpos frios: das coisas que se ensinam às enfermeiras. 2003. Tese (Doutorado em Enfermagem) - Universidade Federal do Rio Grande do Sul, Programa de Pós-Graduação em Educação, Porto Alegre, 2003.

LUNARDI, Valéria Lerch. A ética como o cuidado de si e o poder pastoral na enfermagem. Pelotas: UFPel, 1999.

LUNARDI, Valéria Lerch. Do poder pastoral ao cuidado de si: a governabilidade na enfermagem. 1997. Tese (Doutorado em Enfermagem) - Universidade Federal de Santa Catarina, Programa de Pós-Graduação em Enfermagem, Florianópolis, 1997.

MANDÚ, Edir Nei Teixeira. Intersubjetividade na qualificação do cuidado em saúde. Revista Latino-Americana de Enfermagem, v. 12, n. 4, p. 665-675, 2004.

MUCHAIL, Salma Tannus. Cuidado de si e coragem da verdade. In: GROS, Frédéric. Foucault: a coragem da verdade. São Paulo: Parábola Editorial, 2004.

PAVIANI, Jayme. Interdisciplinaridade: conceito e distinções. Caxias do Sul: Educs, 2005.

RAMOS, Flávia Regina Souza et al. Foucault e enfermagem: arriscando a pensar de outros modos. Index Enfermia, v. 16, n. 57, p. 37-41, 2007.

SANTOS, Jair Licio Ferreira; WESTPHAL, Márcia Faria. Práticas emergentes de um novo paradigma de saúde: o papel da universidade. Estudos Avançados, v. 13, n. 5, p. 71-88, 1999.

SILVA, Graciette Borges da. Enfermagem profissional: análise crítica. São Paulo: Cortez, 1989.

VEYNE, Paul. Foucault: seu pensamento, sua pessoa. Rio de Janeiro: Civilização Brasileira, 2011. 